\title{
Putting the brake on accelerated lung function decline in asthma
}

\author{
Dominic Shaw (1) \\ Affiliation: Nottingham City Hospital, Nottingham, UK.
}

Correspondence: Dominic Shaw, University of Nottingham, Nottingham City Hospital, Hucknall Road, Nottingham, Nottinghamshire, NG5 1PB, UK. E-mail: dominic.shawanottingham.ac.uk

@ERSpublications

Assessing for risk of lung function decline in asthma is important and needs more attention http://ow.ly/L57h30hME3c

Cite this article as: Shaw D. Putting the brake on accelerated lung function decline in asthma. Eur Respir J 2018; 51: 1702630 [https://doi.org/10.1183/13993003.02630-2017].

The focus of most asthma care is on symptom control and exacerbation (attack) prevention. This focus is needed; asthma is a very common disease, still leads to an unnecessarily high symptom burden and is a cause of preventable deaths $[1,2]$. This negative impact occurs despite the recognition that asthma is a heterogeneous disease with various subtypes [3] requiring different treatment approaches [4], with the development of multiple new targeted therapies [5]. Although the identification of biomarkers to help predict exacerbations and understand the interactions between asthma, risk and comorbidities is a key research priority area [6], one of the major problems still affecting our ability to improve asthma outcomes is persuading patients to take potentially lifelong inhaled therapy when, at least for mild and moderate asthma, patients often feel well most of the time.

The work of Coumou et al. [7], published in the European Respiratory Journal this month, offers some insight into this thorny issue. The authors followed the lung function of 141 adults with newly diagnosed asthma for 5 years. Clinical, functional and inflammatory parameters were assessed yearly. Linear mixed-effect models were used to identify predictors of lung function decline. The median change in post-bronchodilator forced expiratory volume in $1 \mathrm{~s}(\mathrm{FEV} 1)$ was $17.5 \mathrm{~mL} \cdot \mathrm{year}^{-1}$ but more importantly, in those patients with a relatively more rapid decline in lung function $\left(>54.2 \mathrm{~mL} \cdot \mathrm{year}^{-1}\right)$, the only associations were a raised exhaled nitric oxide fraction ( $F$ eNO) and low body mass index (BMI) $\left(\leqslant 23 \mathrm{~kg} \cdot \mathrm{m}^{-2}\right)$. The degree of lung function decline observed in this study is comparable to others. In a large Danish study of 17506 subjects followed over 15 years, people with asthma had a decline in their FEV 1 of $38 \mathrm{~mL} \cdot$ year $^{-1}$, compared with $22 \mathrm{~mL} \cdot$ year $^{-1}$ in healthy individuals [8]. Another study found that in people with asthma not treated with inhaled corticosteroids (ICS), the decline in FEV1 was $51 \mathrm{~mL} \cdot$ year $^{-1}$ compared to $25 \mathrm{~mL} \cdot \mathrm{year}^{-1}$ in those receiving treatment [9].

Increased $\mathrm{FeNO}$ in asthma is driven by the upregulation of inducible nitric oxide synthase in the respiratory epithelium via STAT-6 and the proinflammatory Th2 cytokines interleukin (IL)-4 and IL-13. It is often regarded as a surrogate biomarker of Th2-mediated mechanisms within the bronchial mucosa [10]. Multiple studies have examined the utility of FeNO-guided asthma therapy [11]; however, its role and how it should be utilised to guide care has still not been fully defined. The latest Cochrane review concluded that tailoring asthma medications based on FeNO levels (compared with primarily on clinical symptoms) led to a decrease in the frequency of asthma exacerbations but did not impact on day-to-day

Received: Dec 182017 | Accepted: Dec 192017

Conflict of interest: D. Shaw reports receiving advisory board fees from GlaxoSmithKline, Novartis and AstraZeneca, and travel fees from TEVA and AstraZeneca.

Copyright @ERS 2018 
clinical symptoms or ICS dose. The group concluded that the universal use of FeNO to help guide therapy in adults with asthma cannot yet be advocated.

Those familiar with work on FeNO will know that the exhaled gas is extremely sensitive to ICS [12]. This may be the explanation for the association seen in the paper by Coumou et al. [7]. The association between loss of lung function and FeNO levels may simply represent poor concordance with ICS therapy or undertreatment of airway inflammation. This argument is countered by the observation that when comparing patients with and without accelerated decline in lung function, there was no difference in ICS dose, asthma symptoms or airway hyperresponsiveness (AHR). Given that AHR is also sensitive to ICS [13], it is less likely that the effect seen is simply related to ICS dose and hints that there may be a separate inflammatory process at work.

Although the rates of decline in airway disease are well established, predicting and specifically targeting lung function loss is less well evidenced. Chronic airway inflammation is a prime target based on several studies demonstrating a link between FEV1 decline and both eosinophilic [14] and mixed granulocytic inflammation [15]. A cross-sectional study of 1197 people with asthma found that pre-bronchodilator FEV1 was associated with neutrophilic and eosinophilic airway inflammation, whereas sputum total neutrophil counts alone were associated with post-bronchodilator FEV1 [16]

The work of Coumou et al. [7] leads onto an important question, namely whether airway inflammation as represented by increased $F$ eNO, in the absence of symptoms or exacerbations, leads to lung function decline, or whether airway inflammation associated with consequent asthma exacerbations is required for loss of lung function. This is not simply an academic question. It is now well recognised that asthma symptoms are not always linked to exacerbations or airway inflammation [17] and the use of monoclonal therapies predicated on exacerbation rates rather than symptom questionnaires has driven this point home. Using blood eosinophil counts to stratify both risk of exacerbation and response to targeted monoclonal therapy is now firmly embedded in the care of people with difficult asthma; however, we are still not at the point where we can accurately identify those at risk of lung function decline, despite spirometry being the most performed test in people with asthma. Prospectively measuring FeNO at baseline and then treating accordingly would seem an attractive proposition; however, much larger and longer prospective randomised studies of $\mathrm{FeNO}$-guided management are needed to establish this practice.

The relationship between a lower BMI and lung function decline is more difficult to explain. As the authors point out in their conclusion, there are mixed data on the association between body weight and lung function. Although they describe a BMI of $\leqslant 23.05 \mathrm{~kg} \cdot \mathrm{m}^{-2}$ as "lower", a BMI of $18.5-24.9 \mathrm{~kg} \cdot \mathrm{m}^{-2}$ is actually considered healthy. Their mean population BMI of $28 \mathrm{~kg} \cdot \mathrm{m}^{-2}$ would be described as overweight and is a common finding in asthma populations [18]. Moreover, the rate of decline of lung function may not be as important as the trajectory. It is now evident that airflow obstruction relates not only to the rate of decline in FEV1 from a normal starting level of lung function in early adulthood in susceptible individuals, but also from starting at a lower initial baseline FEV1 with a normal decline in FEV1 [19]. Although these data mostly reflect the malign influence of tobacco smoke exposure, it is plausible that occupational exposures, allergens and lung infections may also lead to lung function loss [20] and adversely affect people with asthma.

Given the current focus on exacerbations as the most important end-point in asthma studies and the plethora of new drugs emerging to target specific inflammatory cytokine pathways in fully phenotyped airway disease, this paper is a timely reminder that asthma can be associated with long-term lung function decline and that our patients deserve better prognostic indicators to both manage their day-to-day symptoms and prevent exacerbations, and also prevent potentially disabling lung function loss.

\section{References}

1 McCracken JL, Veeranki SP, Ameredes BT, et al. Diagnosis and management of asthma in adults: a review. JAMA 2017; 318: 279-290.

2 Gibson JG, Loddenkemper R, Sibille Y, et al., eds. European Lung White Book. 2nd Edn. Sheffield, European Respiratory Society, 2013.

3 Haldar P, Pavord ID, Shaw DE, et al. Cluster analysis and clinical asthma phenotypes. Am J RespirCrit Care Med 2008; 178: 218-224.

4 Agusti A, Bel E, Thomas M, et al. Treatable traits: toward precision medicine of chronic airway diseases. Eur Respir J 2016; 47: 410-419.

5 Chung KF. Targeting the interleukin pathway in the treatment of asthma. Lancet 2015; 386: 1086-1096.

6 Walker SM, Akdis C, Dahlen SE, et al. Building the investment case for asthma R\&D: the European Asthma Research and Innovation Partnership argument. Clin Exp Allergy 2016; 46: 1136-1138.

7 Coumou H, Westerhof GA, de Nijs SB, et al. Predictors of accelerated decline in lung function in adult-onset asthma. Eur Respir J 2018; 51: 1701785.

8 Lange P, Parner J, Vestbo J, et al. A 15-year follow-up study of ventilatory function in adults with asthma. $N$ Engl J Med 1998; 339: 1194-1200. 
9 Lange P, Scharling H, Ulrik CS, et al. Inhaled corticosteroids and decline of lung function in community residents with asthma. Thorax 2006; 61: 100-104.

10 Bjermer L, Alving K, Diamant Z, et al. Current evidence and future research needs for FeNO measurement in respiratory diseases. Respir Med 2014; 108: 830-841.

11 Essat M, Harnan S, Gomersall T, et al. Fractional exhaled nitric oxide for the management of asthma in adults: a systematic review. Eur Respir J 2016; 47: 751-768.

12 Martin MJ, Wilson E, Gerrard-Tarpey W, et al. The utility of exhaled nitric oxide in patients with suspected asthma. Thorax 2016; 71: 562-564.

13 Sont JK, Willems LN, Bel EH, et al. Clinical control and histopathologic outcome of asthma when using airway hyperresponsiveness as an additional guide to long-term treatment. The AMPUL Study Group. Am J RespirCrit Care Med 1999; 159: 1043-1051.

14 Ten Brinke A, Zwinderman AH, Sterk PJ, et al. Factors associated with persistent airflow limitation in severe asthma. Am J Respir Crit Care Med 2001; 164: 744-748.

15 Woodruff PG, Khashayar R, Lazarus SC, et al. Relationship between airway inflammation, hyperresponsiveness, and obstruction in asthma. J Allergy Clin Immunol 2001; 108: 753-758.

16 Shaw DE, Berry MA, Hargadon B, et al. Association between neutrophilic airway inflammation and airflow limitation in adults with asthma. Chest 2007; 132: 1871-1875.

17 Tattersfield AE, Postma DS, Barnes PJ, et al. Exacerbations of asthma: a descriptive study of 425 severe exacerbations. The FACET International Study Group. Am J Respir Crit Care Med 1999; 160: 594-599.

18 Shaw DE, Sousa AR, Fowler SJ, et al. Clinical and inflammatory characteristics of the European U-BIOPRED adult severe asthma cohort. Eur Respir J 2015; 46: 1308-1321.

19 Lange P, Celli B, Agustí A, et al. Lung-function trajectories leading to chronic obstructive pulmonary disease. N Engl J Med 2015; 373: 111-122.

20 Kerstjens HA, Rijcken B, Schouten JP, et al. Decline of FEV1 by age and smoking status: facts, figures, and fallacies. Thorax 1997; 52: 820-827. 